\title{
Steroid responsive nephrotic syndrome is more common in Asians
}

\author{
P M SHARPLES, J POULTON, AND R H R WHITE \\ Children's Hospital, Birmingham
}

SUMMARY A retrospective study was undertaken to determine the incidence and compare the natural history of steroid responsive nephrotic syndrome in Asian, European, and AfroCaribbean children born in the United Kingdom and living in Birmingham. Patients were identified from hospital admission records during the years 1979-83. Baseline population data were obtained from the same area using city birth statistics. There were 27 Asian, 13 European, and 2 Afro-Caribbean patients, giving annual incidences of $16,2 \cdot 6$, and $3 \cdot 1$ per 100000 children. The sixfold higher incidence in Asian children remains unexplained; further epidemiological studies may throw new light on the aetiology.

Although there have been several studies of the natural history and renal biopsy findings in steroid responsive nephrotic syndrome on the Indian subcontinent, ${ }^{1}$ there is little available information on its comparative incidence in different racial groups. The present study was initiated because there seemed to be a disproportionate number of Pakistani, Indian, and Bangladeshi children (whom for brevity we shall refer to as Asian) among the nephrotic patients attending this hospital. We were uncertain whether this was a real phenomenon, or an artefact caused by the greater reliance of the Asian community on our casualty department for primary care. We aimed to compare some aspects of the incidence and natural history of steroid responsive nephrotic syndrome in different racial groups in Birmingham.

\section{Methods}

Patients. The study population consisted of children under 16 years of age presenting with the nephrotic syndrome between 1 January 1979 and 31 December 1983, living within the boundaries of the city of Birmingham at the time of diagnosis, and responding to corticosteroid treatment. Names and hospital numbers were traced for all admissions with the main or subsidiary diagnosis of nephrotic syndrome by means of the computerised regional admissions records over this five year period. With the permission of the consultant in charge, the notes were reviewed to confirm the diagnosis and to establish racial origin. All were new presentations, and names and addresses were carefully checked to ensure that no child had been counted twice. Patients known to have been born outside the United Kingdom were excluded (see assumption 4 below). Asians whose birthplace was not recorded were analysed separately to give two estimates of incidence: the low estimate excludes them, the high estimate includes them in the total.

\section{Definitions.}

\section{Nephrotic syndrome}

This was defined as proteinuria of at least $3+$ on Albustix testing, with oedema and a plasma albumin concentration of $25 \mathrm{~g} / 1$ or less.

\section{Steroid response}

Defined as the abolition of proteinuria within eight weeks of starting treatment with prednisolone, usually in daily doses of $60 \mathrm{mg} / \mathrm{m}^{2}$ or $2 \mathrm{mg} / \mathrm{kg}$.

\section{Relapse}

This was defined as recurrence of proteinuria (3+) necessitating further steroid treatment, except in two children who were kept on long term, low dose steroids. In these, relapse was defined as recurrence of proteinuria necessitating an increase in dosage.

\section{Frequent relapsers}

Frequent relapsers were those with at least four relapses per year, or two within six months of diagnosis. $^{2}$

Incidence calculations. In order to calculate the 
incidence $^{3}$ for each group, city records ${ }^{4}$ were consulted for birth statistics by year of birth, based on health visitors' records. Since the patients included in the study were up to 16 years old, it was necessary to obtain birth statistics from the year 1963 . The city boundaries were changed in 1974, and the statistics for 1963-74 did not include Sutton Coldfield Health District. Birth rates for 1963-74 were accordingly taken as the 1975 rates, slightly overestimating the size of the baseline population (see assumption 2). There are no statistics available giving a more accurate estimate of birth cohorts by racial group for this period. These boundaries were identical with those used in selecting the study population. The study population did not contain any children who were known to be of mixed race. It was thought likely that had there been some, they may have been misclassified, on the basis of name and lack of detail in the records, by inclusion in the European group. The incidence figures for Europeans were therefore calculated in two ways: firstly by using only children whose parents were both known to be European, and secondly by using both these and children of mixed race in the denominator. These will be referred to respectively as high and low estimates of the incidence in Europeans.

The following assumptions were made in the calculation of incidence rates:

(1) All new cases of nephrotic syndrome occurring in the city during the study period were firstly diagnosed and secondly treated as inpatients in one of the seven main hospitals, and then entered correctly in the computer.

(2) The 1975 birth statistics were a reasonable estimate for 1963-74. Since birth rates are increasing more in the Asian than the European population, this probably overestimates the earlier Asian births, and underestimates the differences shown.

(3) The migration rate across the city boundaries was the same for all three groups.

(4) The immigration rate into the UK equalled the emigration rates for European children. As there are likely to have been more Asian than European immigrants, the incidence for Asians was calculated in two ways, including and excluding those whose birthplace was not known, to give high and low estimates as above. Both Afro-Caribbeans were known to have been born in the UK.

(5) The death rate from all causes was comparable in all groups. As this is extremely low, differences are unlikely to influence the figures significantly.

\section{Results}

There were 44 patients with this syndrome during the study period: 27 were Asian, 15 European, and 2 Afro-Caribbean. The boy:girl ratio was 3.3:1 for Asians, $0 \cdot 7: 1$ for Europeans $(P<0 \cdot 25$, ns), and $1: 1$ for Afro-Caribbeans (Table 1). The mean age at onset was 3.4 years for Asians, and 4.2 years for Europeans (ns), the modal age for both racial groups occurring between 1 and 3 years. The pattern of relapse was not obviously different in the three racial groups; frequent relapses were recorded in 13 of the 27 Asian patients (48\%), compared with 9 of 15 Europeans $(60 \%)$, and both Afro-Caribbeans (Table 2). Only three patients underwent renal biopsy; the specimens in each case showed minimal changes. ${ }^{5}$

The annual incidence of steroid responsive nephrotic syndrome in Asian children was 16.9 per 100000 children aged under 16 years (high estimate, Table 3). When children whose birthplace was not

Table 1 Incidence of steroid responsive nephrotic syndrome according to sex and ethnic group

\begin{tabular}{llcll}
\hline Ethnic group & \multicolumn{2}{l}{ No of patients } & \multirow{2}{*}{$\begin{array}{l}\text { Ratio } \\
\text { B:G }\end{array}$} \\
\cline { 2 - 5 } & Total & Boys & Girls & \\
\hline Asian & 27 & 21 & 6 & $3 \cdot 3: 1$ \\
European & 15 & 6 & 9 & $0 \cdot 7: 1$ \\
Afro-Caribbean & 2 & 1 & 1 & $1 \cdot 0: 1$ \\
Total & 44 & 28 & 16 & $1.8: 1$ \\
\hline
\end{tabular}

Table 2 Pattern of relapse of steroid responsive nephrotic syndrome according to ethnic group

\begin{tabular}{lcccc}
\hline Ethnic group & $\begin{array}{l}\text { No of } \\
\text { patients }\end{array}$ & \multicolumn{3}{l}{ Pattern of relapse $($ no $(\%))$} \\
\cline { 3 - 5 } & & Frequent & Occasional & Rare \\
\hline Asian & 27 & $13(48)$ & $10(37)$ & $4(15)$ \\
European & 15 & $9(60)$ & $3(20)$ & $3(20)$ \\
Afro-Caribbean & 2 & $2(100)$ & $0(0)$ & $0(0)$ \\
Total & 44 & $24(55)$ & $13(29)$ & $7(16)$ \\
\hline
\end{tabular}

Table 3 Incidence of steroid responsive nephrotic syndrome according to ethnic group

\begin{tabular}{|c|c|c|c|c|c|}
\hline Ethnic group & $\begin{array}{l}\text { No of } \\
\text { patients }\end{array}$ & & $\begin{array}{l}\text { Person } \\
\times 1000\end{array}$ & years & $\begin{array}{l}\text { Annual } \\
\text { incidence } \\
\text { per } 100000\end{array}$ \\
\hline Asian & $\begin{array}{l}\text { High }^{1} \\
\text { Low }^{2}\end{array}$ & $\begin{array}{l}27 \\
25\end{array}$ & & 159 & $\begin{array}{l}16.9 \\
15.7\end{array}$ \\
\hline European & & 15 & $\begin{array}{l}\text { High }^{3} \\
\text { Low }^{4}\end{array}$ & $\begin{array}{l}569 \\
608\end{array}$ & $\begin{array}{l}2 \cdot 6 \\
2 \cdot 5\end{array}$ \\
\hline Afro-Caribbean & & 2 & & 59 & $3 \cdot 4$ \\
\hline Total & & 44 & & 827 & $5 \cdot 3$ \\
\hline
\end{tabular}

High and low estimates:

1 Includes patients of uncertain birthplace.

2 Excludes patients of uncertain birthplace.

3 Excludes patients of mixed race.

4 Includes patients of mixed race. 
recorded were excluded, the annual incidence was still 15.7 per 100000 (low estimate), compared with 2.6 in Europeans (high estimate), and 3.4 in AfroCaribbeans. The European rate falls to $2 \cdot 5$ (low estimate) if children of mixed race are included in the denominator of the incidence calculations for Europeans. This shows that the syndrome is between 6.0 and 6.8 times commoner in Asians in our population. Minimising the contrast between the two groups by using the low Asian estimate and the high European estimate, an approximate test of statistical significance for the difference between these rates gives a $\mathrm{Z}$ value $^{6}$ of $4.07(\mathrm{P}<0.0002)$.

\section{Discussion}

In this series of patients, the age at onset of nephrotic syndrome was similar in Asians and Europeans and comparable with other studies. ${ }^{78}$ Coovadia et al ${ }^{9}$ found a higher proportion of frequent relapsers in Asian than in European children in South Africa, while the reverse was found in our study. Our boy:girl ratio of $0 \cdot 7: 1$ for European children was surprisingly low; previously published data give ratios ranging from 1.96:1 in American children ${ }^{7}$ to $1 \cdot 5: 1$ in Scottish children. ${ }^{8}$ This is probably because of the small number of European patients in this study, and could be expected to be found in $10 \%$ of samples of this size from a population whose true sex ratio was $1 \cdot 5: 1\left(\chi^{2}=2 \cdot 6, n s\right)$. On the small number of patients studied, these findings suggest that the syndrome occurring in Asian children born in the UK is similar in its clinical pattern to that typical of European children.

We believe that these results give a good estimate of the annual incidence of steroid responsive nephrotic syndrome in children aged under 16 years in Birmingham. Assumptions (1), (3), and (5) are unlikely to make significant differences to the figures. Allowing for assumptions (2) and (4), the low estimate of the incidence in Asians is still six times greater than the high estimate in Europeans and is highly significant.

Most studies give an incidence of around 2 per 100000 for children in $\mathrm{USA}^{7}$ and UK, ${ }^{8}$ but we have been unable to find any published incidence figures for Asian children. Feehally et $\mathrm{ll}^{10}$ report annual incidences in Leicestershire of 9.4 and 1.3 patients per 100000 children under 15 years old for Asians and non-Asians respectively. Although these incidences are somewhat lower than ours, they nevertheless support our finding that the incidence is six times greater in Asians. The parents of their patients were predominantly Gujarati Hindus, many having emigrated from East Africa, whereas our patients were mostly Muslims from Pakistan and North India. This reflects the different Asian populations in the two regions, and suggests that the higher incidence of the nephrotic syndrome is not confined to a single cultural group originating in the Indian subcontinent. A paper by Elzouki et al from North Africa ${ }^{11}$ gave an annual incidence of 11.6 per 100000 Arab children aged 0-14 years. There are no obvious reasons for these much higher rates in Asian and Arab children. We found no clusters of patients in time or space. The number of Afro-Caribbean children in this study was too small to permit comment on the relative incidence. One other study has suggested a slightly higher rate in US non-whites (mostly Afro-Caribbeans) than in whites. ${ }^{7}$

Epidemiological comparisons of Asian nephrotic children in the UK and on the Indian subcontinent may help to establish whether this difference is genetic or environmental. Both atopy ${ }^{12}{ }^{13}$ and HLA markers ${ }^{14}$ have been implicated in the aetiology of nephrotic syndrome, and prospective studies need to be done to elucidate whether association with either of these could explain the differences. A recent study suggests that a disproportionate number of patients admitted with acute asthmatic attacks are Asian, compared with the baseline population estimated from census data (Ayres JG, communication, British Thoracic Society, December 1984). This large excess is unlikely to be due to compliance and communication problems alone. There is evidence that manifestations of atopy may be different in Asian asthmatics compared with Europeans, ${ }^{15}$ and it has been suggested that this is influenced by birthplace. ${ }^{1516}$ If the early environment does influence the development of the atopic tendency, the incidence of nephrotic syndrome in Asia might be expected to differ from that in the Birmingham Asian population.

In conclusion, the incidence of steroid responsive nephrotic syndrome is much higher in Asian than in European children aged 0-16 years born in the UK and living in Birmingham. Further studies need to be done to clarify whether this is genetic or environmental, and this may yield new information about aetiology.

We would like to thank Mr T Marshall for help with the statistics.

\footnotetext{
References

1 Srivasta RN, Mayekar G, Anand R, Choudry VP, Ghai OP, Tandon HD. Nephrotic syndrome in Indian children. Arch Dis Child 1975;50:626-30.

2 Report of International Study of Kidney Disease in Children. Prospective controlled trial of cyclophosphamide therapy in children with nephrotic syndrome. Lancet 1974;ii:423-7.

${ }^{3}$ Lilienfield AM, Lilienfield DE. Foundations of epidemiology. Oxford: Oxford University Press, 1980.

4 Birmingham Statistics. Birmingham City Council, 1983.

5 Churg J, Habib R, White RHR. Pathology of the nephrotic syndrome in children. A report of the ISKDC. Lancet 1970;i:1299-302.
} 
${ }^{6}$ Kahn HA. An Introduction to epidemiological methods. New York: Oxford University Press, 1983;157.

7 Schlesinger ER, Sultz HA, Mosher WE, Feldman JG. The nephrotic syndrome. Am J Dis Child 1979;116:623-32.

${ }^{8}$ Arneil GC. 164 children with nephrosis. Lancet 1961;ii:1103-10.

9 Coovadia HM, Adhikari M, Morel-Maroger L. Clinicopathological features of the nephrotic syndrome in South African children. $Q J$ Med 1979;48:77-91.

${ }^{10}$ Feehally $\mathrm{J}$, et al. High incidence of minimal change nephrotic syndrome in Asians. Arch Dis Child 1985;60:1018-1020.

11 Elzouki AY, Amin F, Jaiswal OP. Primary nephrotic syndrome in Arab children. Arch Dis Child 1984;59:253-5.

12 Meadow SR, Sarsfield JK. Steroid responsive nephrotic syndrome and allergy: clinical studies. Arch Dis Child 1981;56: 509-16.
${ }^{13}$ Yap HK, Yip WCL, Lee BW, et al. The incidence of atopy in steroid-responsive nephrotic syndrome: clinical and immunological parameters. Ann Allergy 1983;51:90-4.

14 Thomson PD, Barrat TM, Stokes CR, Turner MW, Soothill JF. HLA antigens and atopic features in steroid responsive nephrotic syndrome. Lancet 1976;ii:765-8.

15 Morrison-Smith J, Cooper SM. Asthma and atopic disease from Asia and the West Indies. Postgrad Med J 1981;57:774-6.

16 Jackson SHD, Bannan LT, Beevers DR. Ethnic differences in respiratory disease. Postgrad Med J 1981;57:777-8.

Correspondence to Dr R H R White, The Children's Hospital, Ladywood Middleway, Birmingham B16 8ET.

Received 7 June 1985

\section{One hundred years ago}

\section{Death from a whipping in school}

\section{The Lancet, 7 November 1885:400}

A few days ago a boy, aged nine, died suddenly in one of the national schools near Dublin under very distressing circumstances. He had been playing truant, and at the request of his father received a switching, by no means very severe. For this purpose he was temporarily placed across a stool. Soon afterwards he dropped upon the floor, and died in a few minutes. A post-mortem examination showed that the deceased was suffering from valvular heart disease with fatty degeneration, and also that the liver was enormously enlarged. The jury, in their verdict, naturally, and probably with good reason, attributed the death to the effect of fright upon a weak and diseased heart. They accordingly exonerated the schoolmaster, but added a somewhat singular injunction-namely, that chastisement should not be administered to children while extended over a seat. Possibly pressure on the enlarged liver may have suggested itself as increasing the already existing cardiac embarrassment. It is not at all unlikely that it did so. This corollary of the verdict cannot, however, be taken to inculpate the schoolmaster in any degree, if it be granted that the punishment was advisable. The real fault lay in having the child at school at all. School inspectors are obliged to be somewhat strict in regulating excuses of absence. In the present case no one could reasonably have objected to such an excuse had it been forthcoming. It may seem strange that no means exists for determining in school the fitness or unfitness of children compulsorily educated for their daily tasks and possible penalties. One method of deciding this point implies the possession by teachers of a certain amount of medical knowledge. This is a good plan so far as it goes, and indeed it is to some extent in operation already, though not under any official provision. A still more practical plan is also to some extent operative-namely, the periodic certification of the health of school children by a medical practitioner. We commend the extension of this practice to the consideration of the authorities concerned in education. 